\title{
Recipient reactions to aid: Effects of locus of initiation, attributions, and individual differences
}

\author{
ANGELICA M. LA MORTO-CORSE and CHARLES S. CARVER \\ University of Miami, Coral Gables, Florida 33124
}

\begin{abstract}
Two studies investigated the experience of obtaining aid. It was hypothesized that attributing need for aid to internal factors would be self-esteem threatening and that under such conditions actively seeking aid would be more aversive than passively accepting aid. No difference in aversiveness was expected when the need was externally attributed. In Experiment 1 , subjects sought less aid when need was internally attributed than when it was externally attributed. In Experiment 2, subjects obtained less aid when they had to seek it than when they could passively accept it, and they obtained less aid when need was internally attributed than when it was externally attributed. The expected interaction between these variables emerged only among persons high in dispositional self-consciousness.
\end{abstract}

Social scientists have long been interested in variables surrounding helping behavior. In the last several years, interest has also arisen in the "other side" of the helping relationship: the recipient's reaction to aid. One general approach to this phenomenon focuses on inferences about why aid is needed. If one's need is caused by circumstances beyond one's control, being helped should be a positive experience. But if the need stems from internal causes, being aided highlights one's personal inadequacy, and the experience should be aversive (e.g., Broll, Gross, \& Piliavin, 1974; Tessler \& Schwartz, 1972).

Another relevant variable is the locus of initiation of the helping act: whether the person must seek out aid or the aid is offered. Which is preferred? Broll et al. (1974) have argued that people prefer to have aid offered, because seeking aid represents an open admission of the need for help. In the absence of contradictory information, the donor (and any other observers) may infer that the aid seeker is inadequate. If aid is offered, on the other hand, the recipient can accept the help, while keeping the inference of inadequacy to a minimum.

Broll et al. (1974) presented data consistent with this reasoning, but others have found the opposite (e.g., Greenberg \& Saxe, 1975). A closer examination of the various studies suggests, however, that the findings may be complementary rather than contradictory. In the Broll et al. (1974) research, need for help reflected a consultant's superior expertise; thus a help request constituted an admission of relative inferiority. In contrast, help seeking in other research did not neces-

This research was the first author's doctoral dissertation, supervised by the second author. Request reprints from Angelica M. La Morto-Corse, Department of Psychology, Grant Center Hospital, 20601 Southwest 157th Avenue, Miami, Florida 33187. sarily imply any personal inferiority. Taken together, the research seems to suggest that one's preference regarding initiation locus may depend heavily on whether the two modes of obtaining aid have different consequences for one's self-esteem (see Nadler, Fisher, \& Streufert, 1976).

Based on the assumption that help seeking entails a declaration of one's need for help, it seems reasonable to predict that donor initiation of an aid attempt should be preferred if need is internally attributed, but that this preference should be lessened if need is attributed to factors outside one's control. Testing these predictions was one purpose of the present research.

A second purpose was to investigate the possible importance for these phenomena of several individual difference variables. Because we assumed mediation by a threat to self, it would seem natural to expect selfesteem to have some impact on the effects. There are at least two logical possibilities in this regard, associated with divergent predictions. One possibility is that negative information about the self violates the selfimages of persons high in self-esteem and is especially disturbing to them, but that such information corroborates the self-images of persons lower in self-esteem and is less disturbing. This analysis suggests that threats to self-esteem would most affect persons high in selfesteem. A second possibility is that lower self-esteem is associated with increased vulnerability to threats to self, and that persons low in self-esteem would be most affected by threatening conditions.

Another variable of interest was dispositional selfconsciousness. Again, there seem to be two possibilities. Self-consciousness leads to an awareness of emotional states (e.g., Scheier \& Carver, 1977) and enhanced responsivity to such states. If threats to self-esteem lead to negative feelings, highly self-conscious persons should be most aware of those feelings. This leads to the prediction that self-consciousness differences would emerge most clearly in conditions of maximum threat. 
An alternative possibility is suggested by Hull and Levy's (1979) argument that self-consciousness involves heightened sensitivity to self-relevant contingencies in one's context. This suggests that self-conscious persons might be particularly sensitive to the attributional contingencies in the experimental setting. This in turn suggests that highly self-conscious persons would best discriminate between threatening (internal attribution) and nonthreatening (external attribution) circumstances.

\section{EXPERIMENT 1 (PILOT)}

\section{Method}

Seven men and 12 women were randomly assigned to the external attribution condition $(n=9)$ or the internal attribution condition $(n=10)$. The experimenter explained to each subject that the researchers were developing techniques to allow people to teach themselves to identify instances of neurotic interaction. The help of college students was being sought in order to ascertain how well these techniques worked. The subject would hear 10 short tape-recorded dialogues, excerpted from the spontaneous interactions of two graduate students, and attempt to identify the degree to which each interaction was neurotic (on 9-point scales). The subject's performance would be evaluated by comparing his or her judgments with ratings made by a team of psychologists.

The experimenter was to be in another room during the task period, so as not to distract the subject. After each dialogue on the tape, subjects were to announce their ratings over an intercom system, and the experimenter would indicate what ratings ostensibly had been given that dialogue by the psychologists. In reality, the experimenter responded to each rating with a value that was 3 to 5 points discrepant (according to a prearranged schedule) from the subject's rating. Thus all subjects were led to perceive their performances to be poor and themselves to be in need of help. Subjects were also informed that an "assistant" would be available to provide help, if help should be desired. This would be in the form of guidelines on how to identify neurotic interaction, ostensibly prepared by the psychologists who had developed the training procedure. All subjects in Experiment 1 were told that they had to initiate the help requests themselves, by pressing a button that would switch on a light in the assistant's room.

Subjects were expected to attribute responsibility for their need for help to external sources (1) if they perceived help seeking to be common in this situation and (2) if there were many rationales available for blaming their own failure on characteristics of the task. Locus of attribution for failure was manipulated by a statement made by the experimenter, indicative that "about $10 \%$ [ or $80 \%$, in the external attribution condition] of the people who have worked on the task have felt that they needed to consult the guidelines," that the psychologists had agreed that subjects were given an adequate (or inadequate) amount of time, and so on. ${ }^{1}$

\section{Results and Discussion}

The dependent measure was the number of times the subject actively requested aid from the assistant. Subjects in the external attribution condition made significantly more attempts to acquire aid (mean $=2.44$ ) than did subjects in the internal attribution condition (mean $=.50) \quad[\mathrm{t}(17)=4.05, \mathrm{p}<.01]$. This finding directly replicates the previous findings of Tessler and Schwartz (1972).

\section{EXPERIMENT 2}

Experiment 2 investigated the more complex relationship between locus of initiation of aid and attribution of failure that was postulated in the introduction. Attribution was manipulated as in Experiment 1, but this time there were two different locus-of-initiation conditions. Some subjects had aid offered to them; others had to seek aid. It was predicted that selfattribution of failure would cause more help to be obtained in the donor-initiated condition than in the recipient-initiated condition. It was also predicted that this preference for donor initiation would be reduced when need was externally attributed. Finally, the role of individual differences was examined in Experiment 2.

\section{Method}

Potential subjects complete a series of questionnaires in group sessions. Chronic selfesteem was measured by the JanisField Scale (Hovland \& Janis, 1959). Self-consciousness was measured by the Self-Consciousness Scale (Fenigstein, Scheier, $\&$ Buss, 1975). Because the most straightforward hypothesis of the study concerned the selfesteem dimension, we used only persons who scored in the top and bottom thirds of the selfesteem distribution $(n=80)$.

The manipulations of attribution were identical to those of Experiment 1 . The recipient-initiation condition used the same instructions as in Experiment 1. Subjects in the donor-initiation condition were told that an assistant would stop at the subject's room and offer guidelines periodically. Each time the assistant appeared, the subject was free to either accept or decline the aid.

After all the sessions, subjects completed a questionnaire, including mood scales, ratings of the assistant, and manipulation checks.

\section{Results}

Manipulation checks. Subjects' ratings of their accuracy indicated that they viewed their performances as poor. Just as important, the groups were equivalent in their perceptions of failure. A check on the manipulations of locus of initiation indicated that they had been successfully encoded. Subjects' accurate processing of attributional information was assessed in several ways. Recall of the percent of previous subjects needing help was generally accurate. Three other items were summed and treated as an index of adequacy of resources (i.è., information and time). Subjects in the external attribution condition should have reported their resources to have been less adequate than subjects in the internal condition (based on the information contained in the experimental instructions). Instead there was an interaction between attribution and locus of initiation $[F(1,64)=3.65, p<.06]$. Comparisons (by Duncan test) revealed that donor-initiation condition subjects given external attributions rated the resources as less adequate (mean $=11.35)$ than did those given internal attributions (mean $=13.10)(p<.05)$. But recipientinitiation subjects reported more moderate reactions to these items in both the internal (mean $=12.20)$ and external $($ mean $=12.70)$ conditions. A question assess- 
ing perceptions of whether it was reasonable to expect students to match the psychologists' ratings yielded a similar interaction $[\mathrm{F}(1,64)=8.25, \mathrm{p}<.01]$. Among donor-initiation subjects, those provided external attributions perceived it to be less reasonable than did those provided internal attributions $(p<.05)$. But subjects in the recipient-initiation condition once again failed to differ from each other as a function of attribution.

These findings suggest that despite accurate recall of the percentage of people needing help in the past, subjects in the recipient-initiation condition failed to accurately encode the specific bits of information that went along with those percentages. This failure may have important implications for the subsequent helpseeking behavior of subjects in this condition.

Help obtained. As in Experiment 1, the major dependent variable was the number of times subjects requested or accepted aid from the assistant. A 2 (attribution) by 2 (locus of initiation) by 2 (self-esteem) analysis of variance (see Table 1) yielded two significant effects. There was a main effect for attribution $[F(1,64)=6.82$, $\mathrm{p}<.02]$, such that external attribution subjects obtained more help (mean $=3.18)$ than did internal attribution subjects (mean $=1.70$ ). This effect was reliable among those in the donor-initiation condition $(p<.05)$, but it did not attain significance in the recipient-initiation condition. The latter was inconsistent with both the results of Experiment 1 and the findings of Tessler and Schwartz (1972).

There was also a main effect for locus of initiation $[F(1,64)=17.20, p<.001]$, such that donor-initiation subjects obtained more help (mean $=2.85)$ than did recipient-initiation subjects $($ mean $=1.50)$.

Self-esteem failed to have any impact whatsoever on help seeking or help acceptance, either alone or in interaction with the experimental manipulations $(\mathrm{Fs}<1)$. Thus our data provide support neither for a cognitive consistency view nor a vulnerability view of the effects of self-esteem.

Self-consciousness. A subsidiary analysis examined the effects of self-consciousness. Subjects were redivided into high and low self-consciousness groups, at the median of the pretest distribution of the "private" subscale of the Self-Consciousness Scale (measuring awareness of covert self-aspects). Analysis of the data broken down in this fashion yielded the same two

Table 1

Mean Instances of Help as a Function of Locus of Attribution, Locus of Initiation, and Self-Esteem, Experiment 2

\begin{tabular}{lccccc}
\hline & \multicolumn{2}{c}{ Low Self-Esteem } & & High Self-Esteem \\
\cline { 2 - 3 } & Mean & SD & & Mean & SD \\
\hline Donor Initiated & 2.30 & 1.64 & 2.40 & 1.17 \\
Recipient Initiated & 1.20 & 1.22 & 1.10 & 1.28 \\
& \multicolumn{4}{c}{ Internal Attribution } \\
Donor Initiated & 3.40 & .96 & 3.30 & .94 \\
Recipient Initiated & 2.10 & 2.51 & 1.60 & 1.34 \\
\hline
\end{tabular}

Table 2

Mean Instances of Help as a Function of Locus of Attribution, Locus of Initiation, and Private Self-Consciousness, Experiment 2

\begin{tabular}{lrrrrr}
\hline & \multicolumn{2}{c}{$\begin{array}{c}\text { Low Self- } \\
\text { Conscious }\end{array}$} & & \multicolumn{2}{c}{$\begin{array}{c}\text { High Self- } \\
\text { Conscious }\end{array}$} \\
\cline { 2 - 3 } \cline { 5 - 6 } \cline { 5 - 6 } & Mean & SD & Mean & SD \\
\hline Donor Initiated & 2.09 & 1.30 & 2.71 & 1.70 \\
Recipient Initiated & 1.13 & 1.36 & 1.27 & 1.19 \\
& \multicolumn{4}{c}{ External Attribution } \\
Donor Initiated & 3.33 & 1.21 & 3.36 & .84 \\
Recipient Initiated & .90 & .99 & 3.38 & 2.20 \\
\hline
\end{tabular}

effects as obtained originally and two effects involving self-consciousness. There was a self-consciousness main effect $[F(1,60)=6.69, p<.02]$, such that highly selfconscious persons obtained more aid overall (mean $=$ 2.68 ) than did less self-conscious persons (mean $=1.74$ ). However, as indicated by a three-variable interaction $[F(1,60)=5.21, p<.03]$, this main effect was largely attributable to the difference between subjects high and low in self-consciousness in the external attribution/ donor-initiation condition (see Table 2 ). Highly selfconscious subjects with an external attribution of need for aid sought far more help than did those lower in self-consciousness $(p<.05)$. A careful examination of Table 2 reveals that when failures were internally attributed, both low and high self-consciousness subjects preferred donor initiation. With external attribution of need, persons low in self-consciousness displayed a similar preference. In marked contrast, persons higher in self-consciousness showed absolutely no preference for donor initiation when attribution was external. Highly self-conscious subjects in these conditions obtained fully as much aid when they had to seek it as when it was offered to them. Stated another way, among highly self-conscious persons, the major prediction of the experiment was supported. This was true even despite the fact that the unexpected interactions on the manipulation-check data (see above) were maintained when those data were reanalyzed by self-consciousness.

We should note that the Self-Consciousness Scale has two additional subscales. Public self-consciousness is awareness of self as a social object; social anxiety is apprehensiveness about displaying oneself in social interaction. It is arguable that these dimensions of self-consciousness should be relevant to the present experimental situation, inasmuch as our reasoning is based in part on self-presentational concerns. Separate analyses, however, yielded no significant effect involving either dimension.

\section{DISCUSSION}

Subjects were given a consistent failure, were led to attribute it either to themselves or to the situation, and were either given offers of aid or required to actively seek any aid desired. As in previous research (Tessler \& Schwartz, 1972), more aid was 
obtained in the external attribution than in the internal attribution condition. There also was a strong tendency for subjects to obtain more aid when they could passively accept it than when they had to seek it. This may reflect a kind of psychological inertia on the part of aid recipients. When the donor approached at regular intervals, aid was accessible. Subjects needed to take no action themselves. Perhaps as a consequence of that fact, they accepted a good deal of aid. Subjects who had to initiate the request, in contrast, had to consciously identify their need and desire for help before obtaining it. Perhaps due to the more complex sequence required, or the responsibility that it entailed, these people were less likely to obtain aid.

This reasoning is complemented by the fact that the aid provided to subjects in this paradigm was not at all effective. Even after consultation, subjects received failure feedback. This should have led the tendency to obtain aid to extinguish. Perhaps, given the greater efforts involved in seeking aid compared with accepting aid, extinction occurred most rapidly among subjects who had to initiate their aid requests. This preference for passive receipt of aid over active aid seeking was expected to be greatest when failure was self-attributed. This interaction occurred in only one restricted case: among persons high in private self-consciousness (see Table 2). This, in turn, resulted in a failure to obtain the predicted interaction when the self-consciousness variable was disregarded. The fact that the predicted pattern was displayed among this set of persons adds credibility to the reasoning behind our prediction, however.

Although the notion of a psychological inertia would account for subjects' tendencies to prefer passive to active aid receipt, manipulation-check results suggest an additional contributing factor, biasing the results in that direction. Manipulation-check data indicated that only subjects in the donor-initiation condition were able to recall correctly all of the attribution-relevant information that had been provided. In effect, subjects in the recipient-initiation condition knew many previous subjects had needed aid but were unable to recall why they had needed that degree of aid. If these groups thus did not differ in attributing their own need, the absence of a difference in aid seeking would not be surprising.

There appear to be two possible explanations for the manipulation-check data, neither of which is wholly satisfactory. The more straightforward possibility is that the study was subject to a sampling bias. The two cells under discussion here were precisely the same experimental conditions as had been investigated in Experiment 1, and virtually the same as those studied by Tessler and Schwartz (1972). Both of the latter studies found reliable differences in aid-seeking behavior between these two groups (although neither incorporated a manipulation check on attribution). This argues that these two cells in Experiment 2 were aberrant. The problem with this explanation is that the sampling bias would have had to be large and consistent in order to lead to the obtained results. This would have been very unlikely to occur by chance.

Another possibility is that the manipulation-check data were distorted by subjects to be consistent with their behavior. This would account for the absence of a difference in self-reports, but it would not account for the absence of a difference in aidseeking. And this behavioral difference is the only result of Experiment 2 that directly contradicts previous findings. Thus this possibility seems unlikely.

\section{Individual Differences}

Self-consciousness. It bears repeating that the predicted interaction between attribution of need for aid and locus of initiation of the aid attempt did occur among persons who were high in dispositional self-consciousness. This was true even despite the fact that the unexpected manipulation-check results were fairly consistent across self-consciousness groups.
This finding has two implications. It suggests that aid seeking in this paradigm is not avoided because of negative affect. If so, the largest behavioral difference between self-consciousness groups should have occurred in the condition of greatest negative affect: the internal attribution/recipient-initiation condition. This was not the case. Instead, the effect appears to have been mediated by an awareness of attributional contingencies and their implications for potential arousal of unpleasant emotions. Thus the greatest self-consciousness difference emerged when attributional contingencies were most important: the external attribution/recipient-initiation condition. The second implication stems directly from this inferred mediational chain. The finding appears to add credibility to Hull and Levy's (1979) contention that self-directed attention can lead to enhanced awareness of self-relevant contingencies in one's behavioral setting.

Self-esteem. Because this research was based in part on the notion that threat to self was a critical mediator of help seeking, the effect of self-esteem level was also examined in Experiment 2 . This variable proved not to be involved in any significant behavioral effect. Earlier effects involving selfesteem (Tessler \& Schwartz, 1972) occurred only when the dimensions of self called into question by aid seeking were central to subjects' self-concepts. Perhaps that is necessary in order for selfesteem to make a difference, and perhaps that centrality of threat was missing from the present study. This reasoning would be consistent with the self-consciousness findings, in that the latter seem to imply a relative absence of subjective affect.

\section{REFERENCES}

Broll, L., Gross, A. E., \& Piliavin, I. Effects of offered and requested help seeking and reactions to being helped. Journal of Applied Social Psychology, 1974, 4, 244-258.

Fenigstein, A., Scheier, M. F., \& Buss, A. H. Public and private self-consciousness: Assessment and theory. Journal of Consulting and Clinical Psychology, 1975, 43, 522-527.

Greenberg, M. S., \& Saxe, L. Importance of locus of help initiation and type of outcome as determinants of reactions to another's help attempt. Social Behavior and Personality, 1975, 3, 101-110.

Hovland, C., \& Janis, I. (Eds.). Personality and persuasibility. New Haven, Conn: Yale University Press, 1959.

Huls, J. G., \& Levy, A. S. The organizational functions of the self. An alternative to the Duval and Wicklund model of self-awareness. Journal of Personality and Social Psychology, 1979, 37, 756-768.

Nader, A., Fisher, J. D., \& Streufert, S. When helping hurts: Effects of donor-recipient similarity and recipient selfesteem on reactions to aid. Journal of Personality, 1976, 44, 392-409.

Scheier, M. F., \& Carver, C. S. Self-focused attention and the experience of emotion: Attraction, repulsion, elation, and depression. Journal of Personality and Social Psychology, 1977, 35, 625-636.

Tessier, R. C., \& Schwartz, S. Help seeking, self-esteem, and achievement motivation: An attributional analysis. Journal of Personality and Social Psychology, 1972, 21, 318-326.

\section{NOTE}

1. This statement was actually somewhat more elaborate. Additional procedural details are available from the first author upon request. 